\title{
PSYCHOLOGICAL AND SOCIAL REACTIONS TO ACUTE SPINAL PARALYSIS
}

By Phillip Harris, F.R.C.S.E., F.R.C.P.E., F.R.C.S.(Glas.), F.R.S.Ed., S. S. Patel, F.R.C.S.E., Miss Wendy Greer, A.I.M.S.W., and J. A. L. Naughton, M.C., B.Sc., M.B., Ch.B.

The Royal Infirmary of Edinburgh, Western General Hospital of Edinburgh and Department of Surgical Neurology, University of Edinburgh

DURING World War II many patients with serious spinal injuries, mostly due to gunshot or shrapnel wounds of the spine, were admitted and treated in the Department of Surgical Neurology in Edinburgh. From an early stage the aim has been to provide a unified and comprehensive service, which includes a full time Medical Social Worker and a Disablement Resettlement Officer. The most important factor is the doctor-patient relationship; this doctor becomes a 'father friend'. Over the years some hundreds of patients with spinal paralysis have been studied and treated, and the psychological and social aspects of these patients have been considered from the moment of admission to hospital, until their eventual discharge home, and beyond this during follow-up assessments.

For this communication we are considering four particular periods and situations: I. the first day of the spinal paralysis; 2 . the first 2 weeks; 3. readmissions because of serious complications and 4. babies born with paraplegia due to myelomeningocoele.

As we have previously reported (Harris, I967), our aim is to have a unified, closely coordinated Spinal Paralysis Service which includes full facilities for patients with spinal paralysis due to trauma, and to other conditions such as spinal neoplasms, acute intervertebral disc protrusions, transverse myelitis and myelomeningocoele. The aetiology of the spinal paralysis is usually a very important factor in determining the patient's psychological reactions to the disability; thus, regarding trauma, did the trauma occur at work or, for example, as the result of an accident while participating in sport. In a mining community there is possibly a greater awareness of serious accidents and as a result the patients, families and their social environment accept such eventualities more easily than they would if the accident occurred in some other circumstance. The immediate reaction of a mother or father of a newborn baby with a myelomeningocoele and paraplegia is, understandably, quite different to that of the parents of a child who has been knocked down in a road traffic accident or who has dived into a shallow pool and sustained a serious spinal injury.

In the acute stage of a patient with a serious spinal injury, pain is very often the main problem and in our experience very often outweighs all other considerations in the patient's mind at this time, and he or she wonders if pain will be present for the rest of their life. The patient requires the situation to be explained, reassurance is as necessary as proper treatment for the pain. Other obvious aspects are the level and completeness of the spinal neural lesion, whether it is progressive or not and whether it is likely to recover. Handling this situation requires considerable experience and excellent judgement on the part of all of the staff involved. 
It is to be remembered that some 30 per cent. of patients with serious spinal traumatic injury have a significant associated injury, usually a head injury. As a result of this the patient may initially be unconscious and there will usually be a period of amnesia and confusion. The family understandably, tend to minimise the gravity of the spinal paralysis in such a situation and there is postponement of the reality of this for days, weeks, or sometimes even months. In high cervical spinal injuries or spinal injuries associated with a chest injury, special intensive therapy for the latter may be essential, including the use of a respirator and the institution of tracheostomy. Thus the situation can be very frightening for the patient. Indeed in the initial period the primary concern of many of these patients and of their near relatives is one of survival. At this stage there is an extreme degree of dependency upon the medical and nursing staff.

We would stress the necessity for the proper initial management of these patients and this may involve transportation by helicopter or aeroplane, or possibly a long ambulance journey. This dramatic turn of events leads to the dissociation of patients from their relatives for a variable period of time and must be fully appreciated by all concerned, including doctors and nurses. The geographical location of the patient's home and that of his family and relations is important; in the acute stage it is recommended that there should be overnight accommodation in the hospital especially for some of the close relatives. It goes without saying that correct expert treatment must be instituted as soon as possible after the spinal paralysis occurs, whether it is due to trauma or to some other cause. The patient and his or her relatives must have immediate and complete faith in the staff and in the whole of the hospital-which should have a very good reputation.

Unfortunately some patients with spinal paralysis develop complications after they have been discharged home which may necessitate re-admission. This may be to a Spinal Paralysis Unit, or to some other hospital for a condition not related primarily or secondarily to the spinal paralysis. Thus again, particular psychological and social problems are liable to arise and must be considered and dealt with in a proper way. A close liaison with the Spinal Paralysis Unit is highly recommended.

When considering the psychological and social reactions of these patients, among many aspects that must be taken into account is the occupation of the patient. Thus, is he the 'bread winner' of the family, or is the patient the housewife and mother? The majority of our patients with traumatic spinal paralysis were young adult males in social classes III, IV and V, that is skilled, semi-skilled and unskilled manual workers. The immediate reactions to spinal paralysis and its consequences are on the whole more readily appreciated in the 'upper social classes'; early reaction in young ambitious professional people, is sometimes one of despair and dejection. Similarly, the family of such upper social class patients initially tend to react with acute disappointment and marked anxiety. Most of our patients were already married when the paralysis occurred and within the first 2 weeks of the onset only a minority of patients began to raise the implication of their disability from the point of view of their future marital and sexual situation. However, in the majority of patients these aspects of disability are constantly at the back of their minds, particularly in the younger age group. In the married group, the wives often raise the issue, but on the whole there can be little acceptance of reality in this short time. There is a definite danger in raising these aspects at this stage, however realistic, unless they are specially mentioned by the patient 
or his immediate family. Thus a full understanding on the part of the medical and nursing staff is imperative. Reaction to disability in this sphere of life is also dependent on the family interrelationship; in fact the family relationship often determines the reaction of patients to their disability.

A knowledge of the past medical history of the patient and his family regarding psychological disturbances can help the doctor to foretell the immediate reaction to acute spinal paralysis. There have been several instances where latent psychopathic or other significant psychiatric abnormalities have been brought to the surface following acute spinal paralysis. If such abnormalities are going to occur they usually appear during the later stages of the illness, that is after the second week, sometimes only after I or 2 months following the onset.

Nowadays the public is much more informed about medical matters; we would refer to Sport for Paraplegics, owed to the genius of Sir Ludwig Guttmann, and to mass media of communication-including the television series 'A Man Called Ironside'. By such means the general public has become more aware of what paraplegia implies and also it is now appreciated that even seriously paralysed people can lead very active and most useful lives.

It is felt that there is an obvious and definite value in patients with recent spinal paralysis, meeting other patients with a similar affliction; contact between relatives is also very useful. We at Edinburgh have a definite policy regarding such meetings and would stress the psychological importance of this to all medical and para-medical personnel involved with the care of people with spinal paralysis. This is another good reason for having such patients in special units and departments; by such contacts patients and relatives soon realise that there is 'always someone worse off than yourself'. However, this whole situation requires very careful handling and occasionally a patient with acute spinal paralysis feels that he can never reach that stage; that he could never perform so well; that he is an amateur and others are professionals. Thus he might initially become somewhat disheartened. However, each situation requires individual management and we are in no doubt that patients can help each other, even in the acute stage of their illness.

It is appreciated that psychological and social reactions result from many personal human biological catastrophies, but those involving spinal paralysis present many special and unique problems. The first concern for the patient and his family is often one of survival, the second is that of the quality of life.

If a wife is able to cope with her own feelings of shock and distress and recognise the moods of her paralysed husband, she can often at this early stage help him to retain his sense of values and self-esteem as a husband and father. There are obvious difficulties for a patient and family if the home situation is already disturbed. A woman recently widowed, fell at home and became paralysed; she was terrified on her admission to hospital, not just because of her injuries but because the experience re-activated her feelings about her husband's death in hospital and she recognised her children's sense of loss and fear that she too may die. The difficulties may be still greater for someone with a disturbed home background and personality problems. There was a young man of 19 from a broken home, his mother was dead and his father an alcoholic, who felt that he had no real home. He therefore found some security and safety in the hospital but at the same time had great difficulty in coping with his disability. This situation compelled him to face his problems squarely, while before his paralysis he tended to act them out by delinquent behaviour. 
Faith, and in particular religious faith, may play an important role in helping the patient, and his relatives in serious illnesses.

Gunther (1969) mentions that the first stage of spinal paralysis, which could be termed 'the stage of shock' may last for several hours or days. During this phase, the individual's thought processes and flow of ideas have considerably slowed down. He appears isolated, confused and numb. His feelings are flat and rather vague. He tends to be unresponsive and somewhat remote when questioned. In general he fails to comprehend what has happened to him. The observer has the impression that the patient does not realise the extent, not to mention the meaning, of the injury. He has not become aware of the emotional meaning of the event. Perhaps this is an unconscious protection against too massive or too rapid a perception of the traumatic and overwhelming reality. Then Gunther goes on to discuss the stage of 'partial recognition and recovery' which may last from a few days to a few weeks. The patient begins to ask more questions and seems to be struggling to recognise his plight, but he protects himself against any awareness of his feelings about this change and he particularly ignores thoughts about his future.

During the first 2 weeks following acute traumatic spinal paralysis questions of compensation concerning insurance and medical legal aspects are unlikely to be raised. But even during this early stage employers may visit the patient and this should certainly be encouraged as it is a tremendous boost to the patient; reassuring him about the possibility of future work prospects and helping him regarding motivation for rehabilitation. The patient's General Practitioner should be notified as soon as possible following the onset of the spinal lesion, should be kept informed of the patient's progress and should be encouraged to visit his patient and to liaise with the family.

One of the authors of this paper (J.A.L.N.), in a previous communication (I963), mentioned that 'there are as many kinds of psychological readjustment as there are people who have to make it. Some face the catastrophe and re-build a personally and sociably valuable life. Clearly, the kind of readjustment they make and have to make, is partly determined by their own personal characteristics, but also to a very important extent by their personal, social and economic circumstances, which are only partly and occasionally modifiable.' 'The human race is remarkably tough and adaptable in the face of real adversity, and within limits is stimulated by it'. Obviously during the early acute stage of his illness, the patient needs support and guidance, but this phase should be kept as short as possible. The patient is prepared to abdicate his adult rights pro tem.'

Complete immobilisation of a patient, in particular a patient with a serious cervical injury, with skull calipers and traction in place, provides an ideal situation for the 'sensory deprivation syndrome' (Zubek, 1964). We have in fact encountered this syndrome in some of our patients; they have hallucinatory-like experiences. We would stress the importance of being aware of this condition and of preventing its occurrence. It can at times be frightening to the staff, especially the nursing staff on duty, particularly at night; and can even be dangerous to the patient.

We feel that patients, and their relatives, should know at an early stage that spinal paralysis is present but this information must be given by a senior person, preferably the Consultant in direct charge of the patient. It is extremely important that there is no undue delay in informing the patient and the relatives regarding the degree and permanency of the paralysis and some idea of what this implies 
for at least the immediate future of the patient. At this stage the patient may be in a state of total despair or of resentment, or even of self-pity. However, if he is still very ill and has pain and possibly also associated injuries, proper contact may not in fact, be possible with the patient at this time. The information should not usually be given on the first day of the spinal paralysis. But the situation is very different regarding the parents of a baby born with a myelomeningocoele; the mother and father should be told as soon as possible that there is a malformation of the spine and that the baby has a degree of spinal paralysis. It is also very important to ensure that the patient and relatives realise that everything possible is being done in the way of investigations and treatment, thus as we have already mentioned, complete confidence in all members of the staff must be obtained at the earliest possible stage.

\section{SUMMARY}

We have brought out various factors relating to the psychological and social reactions to acute spinal paralysis. It is felt that all medical, nursing and other members of the staff should be properly trained and knowledgeable in these aspects of spinal paralysis, as the initial management of such patients-and this also includes the management of the patient's family-will determine the success of subsequent management. We believe that rehabilitation begins from the time of onset of the paralysis and certainly from the time of arrival of the patient in hospital.

Although we realise that the basic pattern of human behaviour is more or less the same everywhere, we are exploring the influence of ethnical differences and different social and cultural influences in different parts of the world on the psychological and social reactions to acute spinal paralysis. Finally, we would stress again the importance of a first-class Spinal Paralysis Service for all patients and proper education of all involved with them, including doctors-specialists and GPs-and all members of the important ancillary and supporting specialties.

\section{REFERENCES}

Gunther, M. S. (1969). Spinal Cord Injuries. Ed. David Ruge. pp. 93. U.S.A.: Charles C. Thomas.

Harris, P. (1967). Paraplegia, V, I32.

Naughton, J. A. L. (1963). Spinal Injuries. Ed. Phillip Harris. Pp. 135. Royal College of Surgeons of Edinburgh.

ZubeK, J. P. (1964). British Medical Bulletin, 20, 38. 